\title{
SOLUÇÃO HIPERSATURADA DE SAL COMO CONSERVANTE DE PERICÁRDIO CANINO UTILIZADO NA REPARAÇÃO DO MÚSCULO RETO ABDOMINAL DE RATOS WISTAR
}

\author{
SUPERSATURATED SALT SOLUTION AS A CANINE PERICARDIUM \\ PRESERVER USED IN REPARATION OF THE \\ RAT RECTUS ABDOMINIS MUSCLE
}

\section{Maurício Veloso Brun ${ }^{1}$ Ney Luis Pippi ${ }^{2}$ David Dreimeier $^{3}$ Emerson Antônio Contesini $^{1}$ Carlos Afonso de Castro Beck ${ }^{1}$ Olicies da Cunha ${ }^{4}$ Saulo Tadeu Lemos Pinto Filho ${ }^{4}$ Claudio Roehsig ${ }^{5}$ Rafael Stedile $^{6}$}

RESUMO

Com a finalidade de testar a solução hipersaturada de sal (na proporção de 1,5g de sal comercial para $1 m \ell$ de água tridestilada) como conservante, foram realizados implantes de pericárdio canino mantido neste meio, no mínimo por 90 dias, em lesões provocadas no músculo reto abdominal de 24 ratos Wistar. Previamente à implantação da membrana, a solução foi avaliada quanto a presença de bactérias e fungos, demonstrando resultados negativos. Durante o procedimento cirúrgico, foi removido um segmento da largura completa do músculo reto abdominal direito, de 1,5cm de comprimento. A lesão produzida foi preenchida com o implante, sendo este suturado às bordas musculares com fio de náilon monofilamentar 6-0 em padrão contínuo simples. Os animais operados foram subdivididos em seis grupos $(I, I I, I I I, I V, V, V I)$ de igual número, sendo posteriormente sacrificados aos três, cinco, sete,10, 15 e 30 dias do pós-operatório, afim de se realizar as avaliações macroscópica e histológica da região do implante. Nos exames macroscópico e histológico pôde-se constatar neovascularização no local reparado, que gradualmente foi decrescendo. Ao exame histológico foi observado a substituição gradativa do implante por tecido conjuntivo fibroso, sem a ocorrência de eliminação do implante ou contaminação. Através destes achados é possível afirmar que a solução hipersaturada de sal estudada, é um meio adequado para a conservação de pericárdio canino.

Palavras-chave: conservação tecidual, solução salina hipersaturada, aloimplante.

\section{SUMMARY}

This study evaluates the supersaturated salt solution (1,5g of commercial salt for $1 \mathrm{~m} \ell$ of tridestilled water) as a tissue preserver. Canine pericardium stored in this medium was implanted in defects made in the rectus abdominis muscle of 24 Wistar rats. Previously the implantation, analysis of the solution was performed and no bacteria or fungi were found. Surgical procedure: a 1,5cm of the right rectus abdominis muscle length was removed, and the defect was covered with the pericardium graft, which was sutured in the muscle borders with a 6-0 monofilamentar nylon using a simple continuous pattern. The rats were subdivided in six similar groups $(I, I I, I I I, I V, V, V I)$, and were euthanized in days $3,5,7,10,15$ and 30 post-operative, respectively. Gross and histological examination showed neovascularization in the surgical site, and it was gradually decreasing. The pericardium was progressively being substituted by fibrous conjunctive tissue, without graft elimination or

${ }^{1}$ Médico Veterinário, Mestre, Aluno do Programa de Pós-graduação em Medicina Veterinária (PPGMV) da Universidade Federal de Santa Maria (UFSM). Rua Paissandu 509, Partenon, 90660-360, Porto Alegre, RS. E-mail:mbrun@zipmail.com.br. Autor para correspondência.

${ }^{2}$ Médico Veterinário, Mestre, Doutor, Professor do PPG em Medicina Veterinária da UFSM.

${ }^{3}$ Médico Veterinário, Mestre, Doutor, Professor do PPG em Ciências Veterinárias da Universidade Federal do Rio Grande do Sul.

${ }^{4}$ Médico Veterinário, Aluno do PPG em Medicina Veterinária da UFSM.

${ }^{5}$ Médico Veterinário, Residente da Universidade Estadual de Londrina.

${ }^{6}$ Acadêmico do Curso de Medicina Veterinária da UFSM. 
contamination. Supersaturated salt solution therefore offers an adequate storage system to the canine pericardium.

Key words: tissue preservation, supersaturated salt solution, alograft.

\section{INTRODUÇÃO}

A reparação de defeitos musculares com a aplicação de tecidos biológicos conservados em diferentes meios tem sido amplamente descrita na literatura (STOLF $\boldsymbol{e} \boldsymbol{t}$ al., 1978; RODGERS $\boldsymbol{e t}$ al., 1981; DALECK et al., 1988). Uma das soluções mais utilizadas para esta finalidade é a glicerina a $98 \%$, que mantém as características do tecido conservado, possui propriedades desidratantes, antisépticas e antiimunogênicas, é pouco dispendiosa (PIGOSSI, 1964; PIGOSSI, 1967; ALVARENGA, 1977; DALECK et al., 1987; ALVARENGA, 1992), aumenta a resistência à tração (PIGOSSI et $\boldsymbol{a l}$., 1967) e atua como arcabouço para o crescimento tecidual no leito receptor (DALECK $\boldsymbol{e t}$ al., 1988; OLIVEIRA et al., 1999). O pericárdio eqüino ou bovino quando conservado neste meio, e utilizado tanto em ensaios clínicos como experimentais, revelou ótimas qualidades e não apresentou sinais de rejeição (RANZANI $\boldsymbol{e} \boldsymbol{t} \boldsymbol{a l}$., 1990; LAVALLE $\boldsymbol{e} \boldsymbol{t} \boldsymbol{a l}$., 1998; BRUN et al., 2000). Apesar dos resultados satisfatórios relacionados ao uso da glicerina, estudos são desenvolvidos na busca de outras soluções conservantes.

SUBRAHMANYAM (1993) estudou o mel não processado como meio de conservação de pele para enxertos em 28 pacientes humanos. Após um período mínimo de duas semanas, as peles armazenadas foram implantadas para o tratamento de queimaduras e úlceras, não demonstrando sinais de autólise ou alteração histológicas. AMENDOLA (2001) realizou, em seis cães, a implantação de osso cortical homógeno conservado em mel durante um período mínimo de 30 dias. Este tecido foi colocado sobre uma falha óssea produzida no fêmur e fixado com cerclagem de aço. No acompanhamento radiográfico foi verificado que, aos 60 dias após a operação, dois animais apresentaram reabsorção completa do osso homógeno, enquanto nos demais o implante estava em franco processo de incorporação. AMENDOLA et al. (2000) procederam a terapêutica cirúrgica de defeitos parciais na traquéia de coelhos com centro frênico canino conservado em mel. Sessenta dias após o procedimento, foi observada epitelização completa sobre o tecido implantado.

Solução hipersaturada de açúcar, na proporção de $3 \mathrm{~g}$ de açúcar comercial para $1 \mathrm{ml}$ de água tridestilada, também tem sido utilizada como meio de conservação de materiais biológicos. GONÇALVEZ (2000) realizou ceratoplastia lamelar bilateral em cães com córneas homógenas mantidas em solução hipersaturada de açúcar ou em glicerina a 98\%. As avaliações histológicas permitiram a constatação inicial de processo inflamatório com neovascularização abundante e reepitelização completa, após 15 dias ao implante, seguido de proliferação de colágeno com acantose e de involução vascular, aos 30 e 60 dias após a implantação, respectivamente. Ambos os implantes demonstraram resultados semelhantes e não apresentaram sinais de rejeição. MAZZANTI (2000) ao reparar experimentalmente defeitos diafragmáticos extensos em cães com músculo diafragma homógeno conservado em solução de açúcar constatou substituição parcial ou total do implante, dependendo do tempo de observação, que variou entre 30,75 ou 120 dias, por tecido fibrovascular, sem a ocorrência de rejeição ou infecção bacteriana.

Com o objetivo de se testar a viabilidade da solução hipersaturada de sal, na proporção de $1,5 \mathrm{~g}$ de sal comercial para $1 \mathrm{~m} \ell$ de água tridestilada, como conservante de tecidos biológicos, foi realizada a implantação de pericárdio canino mantido neste meio por um período mínimo de 90 dias em falha provocada no músculo reto abdominal de ratos Wistar, sendo os resultados analisados em diferentes tempos, através de exames histológicos.

\section{MATERIAL E MÉTODOS}

Foram utilizados 24 ratos Wistar escolhidos ao acaso, fêmeas hígidas, de idade superior a 90 dias, fornecidos pelo Biotério Central da UFSM. Durante todo o experimento os animais foram mantidos em gaiolas adequadas, recebendo como fonte nutricional ração comercial e água $a d$ libitum. Em todas as ratas se realizou a implantação do pericárdio canino, após a qual os animais foram separados ao acaso em seis grupos de quatro indivíduos cada, denominados I, II, III, IV, V e VI.

A membrana foi coletada, de forma não asséptica, de um canino adulto que não apresentou sinais clínicos e hematológicos de doença infectocontagiosa. Após a remoção dos tecidos adjacentes, $\mathrm{o}$ pericárdio foi lavado em água corrente $\mathrm{e}$ depositado em frasco limpo contendo solução de sal comercial $^{\mathrm{a}}$ e água tridestilada, sendo esta obtida através da homogeneização, em liquiidificador, de $300 \mathrm{~g}$ do sal com $200 \mathrm{~m} \ell$ de água. A membrana foi mantida nesse meio em temperatura ambiente por 
um período mínimo de 90 dias. Decorrido esse período de conservação, uma amostra do líquido conservante foi avaliada quanto à presença de bactérias e fungos, utilizando-se os meios agar sangue (AS), brain heart infusion (BHI), thioglycollate (TIO), micobiotic e sabouraud choranphenicol agar.

Previamente à cirurgia, um segmento do pericárdio conservado foi abundantemente irrigado com solução de cloreto de sódio a $0,9 \%$, a fim de se remover a maior quantidade possível do conservante. Na sequiência, o implante foi mantido submerso na solução previamente descrita por um período mínimo de 15 minutos, para a hidratação, e uma amostra foi coletada para a análise histológica.

Como protocolo anestésico, utilizou-se a associação de cloridrato de xilazina ${ }^{c}$ na dose de $5 \mathrm{mg} / \mathrm{kg}$, via intramuscular (IM) e cloridrato de cetamina $^{\mathrm{d}}$ na dose de $50 \mathrm{mg} / \mathrm{kg}$ IM, sendo o primeiro fármaco aplicado cinco minutos antes do segundo. Quando o animal estava em plano adequado, realizou-se ampla tricotomia da região operatória. $\mathrm{Na}$ seqüência, os animais foram colocados em decúbito dorsal na mesa operatória, e se realizou a anti-sepsia do campo operatório com a aplicação de álcool iodado. Cinco minutos antes do procedimento cirúrgico foi administrada ampicilina sódica ${ }^{\mathrm{e}}$, na dose de $20 \mathrm{mg} / \mathrm{kg}$, via intraperitonial.

Realizou-se, na linha média ventral, uma incisão de pele de aproximadamente dois centímetros e meio de comprimento. O tecido subcutâneo foi dissecado com a utilização de tesoura Metzembaum até alcançar o folheto externo do músculo reto abdominal. Uma pinça Halsted foi utilizada na apreensão, em conjunto, do folheto externo e músculo reto abdominal direito. Com o tracionamento da pinça, foi removido um segmento de um centímetro e meio de comprimento, da largura completa do músculo. Durante esta manobra, procurou-se preservar, por meio de dissecação romba, o folheto interno do músculo reto abdominal e o peritônio. Quando houve a ruptura destes tecidos, o folheto interno foi incluído na sutura de fixação da membrana.

A lesão provocada foi reparada com implante de pericárdio de cão, de dimensões compatíveis com o defeito provocado. Este, foi suturado à linha alba, aos músculos obliquo abdominal externo e interno, e ao músculo reto abdominal direito com fio monofilamentar de náilon 6- $0^{\mathrm{f}}$, em padrão contínuo simples. Na seqüência, o tecido subcutâneo foi suturado com o mesmo fio e em mesmo padrão. A aposição das margens da pele foi realizada com fio semelhante em padrão isolado simples.
Os animais dos grupos I, II, III, IV,V e VI foram sacrificados aos três, cinco, sete, 10,15 e 30 dias após o procedimento cirúrgico, respectivamente. A região do implante foi analisada quanto à presença de: macrófagos; fibrina $\mathrm{e}$ neutrófilos; tecido de granulação e proliferação vascular; fibrose; e manutenção da membrana implantada. A cada uma destas características, foi atribuída uma escala em cruzes, na qual 0 correspondia à ausência, e $1+, 2+$ e $3+$ correspondiam a pequena, moderada ou acentuada presença da característica, respectivamente.

\section{RESULTADOS E DISCUSSÃO}

Não ocorreu crescimento de bactérias ou fungos nas análises microbiológicas. Durante o acompanhamento pós-operatório e nos exames macroscópico de necropsia e histológico, também não se constatou a presença destes agentes, tanto no implante como no tecido receptor. Tais observações demonstram que a solução hipersaturada de sal possui propriedades anti-sépticas, uma vez que o pericárdio foi coletado de forma não asséptica e não foram empregados antibióticos durante o período pós-operatório. De forma semelhante, foi demonstrado, em estudos prévios, que a glicerina a 98\% impede o crescimento bacteriano ou fúngico (ALVARENGA, 1977; DALECK et al., 1988; BRUN et al., 2000). PIGOSSI (1967) afirma que este meio possui forte ação bactericida, com exceção para as formas esporuladas. Outros meios como a solução hipersaturada de açúcar e o mel também possuem ação antimicrobiana (CHIRIFE et al., 1982; GREENWOOD, 1993; POSTMES et al., 1993). CHIRIFE et al. (1982) afirmam que o açúcar atua através da criação de um ambiente de baixa atividade de água, o que inibe o crescimento das bactérias. Os autores do presente trabalho acreditam que a ação antibacteriana e antifúngica da solução hipersaturada de sal também é centralizada na diminuição da atividade de água, contudo, não descartam a possibilidade de que o iodo (presente no sal comercial) atue neste sentido.

Ainda em relação aos diferentes meios, o mel apresenta a possibilidade de contaminação por resíduos de pesticidas e de fármacos, tais como a tetraciclina, utilizados no tratamento de doenças das abelhas (POSTMES et al., 1993). Estas condições não estão presentes quando se utiliza soluções hipersaturadas de açúcar ou sal como conservantes.

Antes de se implantar uma membrana conservada em soluções desidratantes, torna-se necessário realizar a sua hidratação. $\mathrm{O}$ protocolo utilizado para este fim por diferentes autores 
apresenta grande variação, na dependência do material conservado. RAISER (2000), ao implantar tendões homógenos conservados em glicerina, advoga um período de hidratação de 24 horas em solução hidroeletrolítica balanceada com polivinilpirrolidona a 1\%, na diluição de 1:50. PIGOSSI (1964) preconiza um período de cinco minutos de imersão em $\mathrm{NaC} \ell 0,9 \%$ para duramater canina conservada neste meio. OLIVEIRA $\boldsymbol{e t} \boldsymbol{a l}$. (1999) apregoam a hidratação de bexigas conservadas em glicerina por um tempo mínimo de 20 minutos. Já DALECK et al. (1988), RANZANI $\boldsymbol{e t}$ al. (1990) e DALECK et al. (1992) indicam que membranas (peritônio bovino ou pericárdio equiino) mantidas neste meio devem permanecer em solução de $\mathrm{NaC} \ell$ 0,9\%, acrescida de 500mg de ampicilina, por um período de 10 minutos.

De forma semelhante aos estudos envolvendo a implantação de tecidos conservados em solução hipersaturada de açúcar (GONÇALVES, 2000; MAZZANTI, 2000), o período mínimo de 15 minutos demonstrou ser adequado para hidratar o pericárdio conservado em sal, contudo torna-se necessário que previamente se remova o excesso desta substância por meio de irrigação abundante. Quanto à utilização de antibióticos no líquido de hidratação, os autores do presente estudo acreditam que esta seja uma prática desnecessária, uma vez que não foram encontradas bactérias ou fungos na análise histológica do implante, e não ocorreu crescimento destes organismos nos meios nutrientes. Tal posicionamento é compartilhado por GONÇALVES (2000) em relação às córneas conservadas em glicerina ou em solução de açúcar. A aplicação de antibiótico no período pré-operatório visou apenas diminuir a possibilidade de contaminação proveniente do ambiente cirúrgico durante o procedimento.

Ao exame macroscópico da membrana, evidenciou-se a coloração esbranquiçada desta, e a manutenção de sua maleabilidade, mesmo antes do período de hidratação. Tal característica facilitou a manipulação do implante durante o procedimento cirúrgico. Ao exame histológico, foi constatado que o pericárdio manteve seu arcabouço conjuntivofibrilar, porém as células demonstraram a ausência de núcleos. Achados microscópicos semelhantes foram encontrados por RAZANI et al. (1990), ao estudarem pericárdio eqüino mantido em glicerina. Esses resultados sugerem que o processo de conservação de ambos os meios é semelhante. A ausência da vitalidade da membrana estudada é uma condição que não interfere no sucesso de sua implantação, uma vez que este é diretamente relacionado à reação de reparação do tecido hospedeiro (PIGOSSI, 1964, 1967).

Não ocorreram complicações anestésicas ou cirúrgicas nos 24 animais operados. A duração das cirurgias variou de 21 a 37 minutos, com tempo médio de 26,8 minutos. Durante a etapa de dissecção do músculo reto abdominal ocorreu a ruptura do folheto interno e peritônio em 15 animais. Dez destes demonstraram aderências na região do implante com as seguintes estruturas intracavitárias: omento maior (4), ligamento largo do útero (3), omento e ligamento largo (2), ligamento lateral da bexiga (1). Em dois animais, foi observada a aderência do omento ou ligamento largo sem a constatação da ruptura do folheto interno durante o procedimento cirúrgico. Nenhuma das aderências demonstrou significado clínico, e a inclusão do folheto interno na sutura de reparação do defeito não foi efetiva para evitá-las.

Ao exame macroscópico, foi possível reconhecer em todos os animais a localização do implante, tanto pela sua coloração diferenciada quanto pela presença do fio de sutura. Em todos os casos o defeito muscular estava adequadamente preenchido pelo pericárdio, não sendo observadas reações de eliminação da membrana ou contaminação na área operada. Nos animais do grupo I (três dias após o procedimento), o tecido subcutâneo estava amplamente aderido ao implante, e a neovascularização local era visível. Na face interna do músculo reto abdominal, evidenciou-se crescimento vascular proveniente das bordas da lesão e na porção ventral do implante. Aos cinco dias após a operação (grupo II), as alterações externas foram semelhantes às descritas anteriormente, contudo na face interna da parede abdominal a neovascularização apresentava-se mais pronunciada. Aos sete dias (grupo III), o quadro se manteve sem alterações. Aos 10 dias (grupo IV), a vascularização local apresentava-se em processo de regressão. Nos animais do grupo V (15 dias após a cirurgia) já se tornava difícil a delimitação das bordas do implante, dando-se a impressão de que o pericárdio estava sendo substituído pelo tecido receptor. A neovascularização mostrava-se em retrocesso. Aos 30 dias (grupo VI) não se evidenciaram alterações no tecido subcutâneo, e a região do implante apresentava-se discretamente irrigada. A membrana implantada parecia ter sido completamente substituída por tecido fibroso.

Histologicamente, foi evidenciado nos animais do grupo I que o pericárdio manteve suas características inalteradas. Ocorreu formação de fibrina e presença de neutrófilos de forma acentuada (3+), associada a discreto início de proliferação 
vascular (1+). Também se observou migração moderada de macrófagos para a área implantada (2+). Já no grupo II, pode-se constatar a diminuição do tamanho da membrana com infiltração moderada a acentuada de macrófagos, sendo que tais células também foram evidenciadas ao redor dos fios de sutura. A presença de fibrina e neutrófilos estava diminuída em relação à observação anterior $(2+)$. A proliferação vascular e o tecido de granulação demonstraram amplo desenvolvimento, e por vezes, observou-se a presença de células gigantes. A resposta inflamatória era maior nas bordas da membrana. Em alguns casos, constatou-se pequeno acúmulo de exsudato inflamatório em uma microcavidade (seroma). Os animais do grupo III não demonstraram grande variação em relação ao grupo anterior, contudo ocorreu diminuição da quantidade de fibrina e neutrófilos $(1+)$, e o início de fibrose na região implantada $(1+)$. No grupo IV se observou pequena quantidade de fibrina $e$ neutrófilos associada à acentuada proliferação do tecido de granulação. A infiltração macrofágica era evidente $(3+)$, por vezes com células gigantes. A presença do implante na área operada era moderada. Aos 15 dias após as cirurgias (grupo V), a fibrose tornava-se mais pronunciada, e o tecido de granulação demostrava em regressão $(2+)$. Nos ratos do grupo VI, foi constatada a presença acentuada de fibrose no local de implante, associada ao desaparecimento total do pericárdio. Notava-se a ausência de neutrófilos e fibrina. $O$ tecido de granulação demonstrava involução (1+), e foram observados alguns pequenos aglomerados de células linfoplasmocitárias. As avaliações histológicas da região do implante encontram-se relacionadas na tabela 1.

No exame macroscópico de necropsia e nas avaliações histológicas, ficou demonstrada a ocorrência de uma reação inflamatória aguda, que gradativamente foi desaparecendo, seguida da substituição do implante (parcial ou total, dependendo do período de observação) por tecido conjuntivo fibroso. Tal padrão de reposta tem sido evidenciado em estudos envolvendo diferentes materiais biológicos conservados em solução de glicerina ou hipersaturada de açúcar (PIGOSSI, 1964, 1967; DALECK et al., 1987; DALECK $\boldsymbol{e t}$ al., 1988; RAZANI et al., 1990; OLIVEIRA et al., 1999; RAISER, 2000; MAZZANTI, 2000), e demonstra que o pericárdio canino mantido na solução de sal estudada também atua como um arcabouço para o crescimento do tecido vivo.

Reações tipo corpo estranho ou eliminação do implante não foram detectadas, isso talvez seja indicativo de que a solução hipersaturada de sal possua função antiimunogênica, característica que também tem sido constatada em outros meios de conservação como a glicerina a 98\% (PIGOSSI, 1964; PIGOSSI, 1967; DALECK et al., 1987; OLIVEIRA et al., 1999; RAISER, 2000), solução hipersaturada de açúcar (GONÇALVEZ, 2000; MAZZANTI, 2000) e mel não processado (AMENDOLA, 2001). Tal função é de suma importância para um meio conservante, uma vez que dispensa a utilização de drogas imunosupressoras durante os períodos trans e pós-operatórios. PIGOSSI (1964, 1967) e RANZANI et al. (1990) atribuem a baixa antigenicidade dos materiais biológicos mantidos em glicerina devido ao processo de conservação deste meio.

Cabe relembrar que o uso de membranas biológicas conservadas pode demonstrar vantagens sobre o das próteses sintéticas em cirurgias reparadoras, devido a possibilidade de sua incorporação ao organismo receptor (PIGOSSI, 1967; DALECK et al., 1988), suas resistências à infecção, e à capacidade de serem moldadas ao defeito existente (RODGERS et al., 1981).

A solução descrita necessita de matéria prima de fácil obtenção, é produzida de forma rápida e simples, é pouco onerosa e demonstra ser adequada para a conservação de pericárdio canino. Segundo o conhecimento dos autores, este é o primeiro relato que descreve a utilização de solução hipersaturada de sal para a conservação de membrana biológica.

\section{CONCLUSÕES}

Nas condições do presente estudo, podese concluir que a solução hipersaturada de sal, na proporção de $1,5 \mathrm{~g}$ de sal comercial para $1 \mathrm{~m} \ell$ de água tridestilada, pode ser utilizada na conservação de pericárdio canino devido a suas propriedades antisépticas e a sua possibilidade de manter as características estruturais do implante.

O pericárdio canino conservado em solução hipersaturada de sal atua como um arcabouço para o crescimento do tecido vivo.

\section{FONTES DE AQUISIÇÃO}

${ }^{\mathrm{a}}$ Cisne churrasco, Cabo Frio, RJ

${ }^{\text {b}}$ Cloreto de sódio, Texon, Viamão, RS.

${ }^{c}$ Rompum, Bayer, Porto Alegre, RS

${ }^{\mathrm{d}}$ Ketamin-S, Cristália, Itapira, SP.

${ }^{\mathrm{e}}$ Ampicilina, Ariston, São Paulo, SP.

${ }^{\mathrm{f}}$ Nylonpoint 6-0, Point Suture do Brasil, Fortaleza - CE. 
Tabela 1 - Distribuição dos aspectos analisados, em escala de 0-3+, em 24 ratos Wistar submetidos à reparação do músculo reto abdominal com implante de pericárdio canino conservado em solução hipersaturada de sal, nos períodos de avaliação de três, cinco, sete, 10 , 15 e 30 dias após o procedimento cirúrgico (grupos I, II, III, IV, V e VI, respectivamente).

\begin{tabular}{|c|c|c|c|c|c|c|}
\hline GRUPO & IDENTIFICAÇÃO & $\begin{array}{c}\text { FIBRINA E } \\
\text { NEUTRÓFILOS }\end{array}$ & MACRÓFAGOS & $\begin{array}{l}\text { TEC. GRANUL. E } \\
\text { PROL. VASCULAR }\end{array}$ & FIBROSE & $\begin{array}{l}\text { PRESENÇA DO. } \\
\text { IMPLANTE }\end{array}$ \\
\hline I & $\begin{array}{l}\text { animal } 1 \\
\text { animal } 2 \\
\text { animal } 3 \\
\text { animal } 4\end{array}$ & $\begin{array}{l}3+ \\
3+ \\
3+ \\
3+\end{array}$ & $\begin{array}{l}2+ \\
1+ \\
2+ \\
3+\end{array}$ & $\begin{array}{c}1+ \\
0 \\
1+ \\
1+\end{array}$ & $\begin{array}{l}0 \\
0 \\
0 \\
0\end{array}$ & $\begin{array}{l}3+ \\
3+ \\
3+ \\
3+\end{array}$ \\
\hline II & $\begin{array}{l}\text { animal } 5 \\
\text { animal } 6 \\
\text { animal } 7 \\
\text { animal } 8\end{array}$ & $\begin{array}{c}2+ \\
2+ \\
2+ \\
0\end{array}$ & $\begin{array}{l}3+ \\
2+ \\
3+ \\
2+\end{array}$ & $\begin{array}{l}3+ \\
3+ \\
3+ \\
2+\end{array}$ & $\begin{array}{l}0 \\
0 \\
0 \\
0\end{array}$ & $\begin{array}{l}2+ \\
3+ \\
2+ \\
3+\end{array}$ \\
\hline III & $\begin{array}{c}\text { animal } 9 \\
\text { animal } 10 \\
\text { animal } 11 \\
\text { animal } 12\end{array}$ & $\begin{array}{l}1+ \\
1+ \\
3+ \\
1+\end{array}$ & $\begin{array}{l}3+ \\
3+ \\
2+ \\
3+\end{array}$ & $\begin{array}{l}3+ \\
3+ \\
1+ \\
3+\end{array}$ & $\begin{array}{c}0 \\
1+ \\
0 \\
1+\end{array}$ & $\begin{array}{l}2+ \\
2+ \\
3+ \\
2+\end{array}$ \\
\hline IV & $\begin{array}{l}\text { animal } 13 \\
\text { animal } 14 \\
\text { animal } 15 \\
\text { animal } 16\end{array}$ & $\begin{array}{l}2+ \\
1+ \\
1+ \\
1+\end{array}$ & $\begin{array}{l}2+ \\
3+ \\
3+ \\
3+\end{array}$ & $\begin{array}{l}2+ \\
3+ \\
3+ \\
3+\end{array}$ & $\begin{array}{c}2+ \\
1+ \\
0 \\
1+\end{array}$ & $\begin{array}{l}2+ \\
2+ \\
2+ \\
2+\end{array}$ \\
\hline V & $\begin{array}{l}\text { animal } 17 \\
\text { animal } 18 \\
\text { animal } 19 \\
\text { animal } 20\end{array}$ & $\begin{array}{c}0 \\
1+ \\
1+ \\
2+\end{array}$ & $\begin{array}{l}3+ \\
2+ \\
3+ \\
2+\end{array}$ & $\begin{array}{l}2+ \\
2+ \\
3+ \\
2+\end{array}$ & $\begin{array}{l}2+ \\
3+ \\
1+ \\
1+\end{array}$ & $\begin{array}{c}0 \\
2+ \\
2+ \\
2+\end{array}$ \\
\hline VI & $\begin{array}{l}\text { animal } 21 \\
\text { animal } 22 \\
\text { animal } 23 \\
\text { animal } 24\end{array}$ & $\begin{array}{l}0 \\
0 \\
0 \\
0\end{array}$ & $\begin{array}{c}2+ \\
1+ \\
0 \\
2+\end{array}$ & $\begin{array}{c}2+ \\
0 \\
1+ \\
1+\end{array}$ & $\begin{array}{l}3+ \\
3+ \\
3+ \\
3+\end{array}$ & $\begin{array}{l}0 \\
0 \\
0 \\
0\end{array}$ \\
\hline
\end{tabular}

TEC. $=$ TECIDO; PROLIF. $=$ PROLIFERAÇÃO

\section{REFERÊNCIAS BIBLIOGRÁFICAS}

ALVARENGA, J. Possibilidades e limitações da utilização de membranas biológicas preservadas em cirurgia. In: DALECK, C.R. Tópicos em cirurgia de cães e gatos. Jaboticabal : Fundação de estudos e pesquisas em Agronomia - Universidade Estadual Paulista, 1992. p.33-39.

ALVARENGA, J. Substituição de segmento de colédoco em cães por preparado de pericárdio homólogo conservado em glicerina. São Paulo, SP, 1977. 101p. Tese (livre Docência) - Faculdade de Medicina Veterinária e Zootecnia, Universidade de São Paulo, 1977.

AMENDOLA, G.F. Correção de defeito ósseo femural em cães utilizando implante ósseo cortical homólogo conservado em sal. Santa Maria, 2001. 46p. Dissertação (Mestrado em Medicina Veterinária, área de concentração em Cirurgia) Programa de Pós-graduação em Medicina Veterinária, Universidade Federal de Santa Maria, 2001.
AMENDOLA, G.F., SCHOSSLER, J.E.W., OLIVEIRA, S.T., $\boldsymbol{e} t$ al. Traqueoplastia em coelhos com centro frênico canino conservado em mel. Ciência Animal Brasileira, v.1, suplemento, p.111, 2000.

BRUN, M.V., PIGATTO, J.A.T., BECK, C.A.C., et al. Traqueoplastia em cães com pericárdio eqüino conservado em glicerina por um período de 11 anos. Revista Brasileira de Ciência Veterinária, v.7, suplemento, p.58, 2000.

CHIRIFE, J., SCARMATO, G.A., HERSZAGE, L. Scientific basis for use of granulated sugar in treatment of infected wounds. The Lancet, p.560-561, Mar. 1982.

DALECK, C.R., DALECK, C.L.M., ALESSI, A.C., et al. Substituição de um retalho diafragmático de cão por peritônio de bovino conservado em glicerina: estudo experimental. Ars Veterinária, v.4, n.1, p.53-61, 1988.

DALECK, C.R., DALECK, C.L.M., PADILHA FILHO, J.G., $\boldsymbol{e} t$ al. Reparação de hérnia perineal em cães com peritônio de bovino conservado em glicerina. Ciência Rural, v.22, n.2, p.179-183, 1992. 
DALECK, C.R., GANDOLFI, W., DALECK, C.L.M., et al. Esofagoplastia cervical em cão com peritônio autólogo ou homólago conservado em glicerina -“estudo experimental”. Ars Veterinária, v.3, n.2, p.195-202, 1987.

GONÇALVES, G.F. Ceratoplastias lamelar homóloga em cão com conservação em solução supersaturada de açúcar ou glicerina. Santa Maria, RS, 2000. 54p. Dissertação (Mestrado em Medicina Veterinária, área de concentração em Cirurgia) - Programa de Pós-graduação em Medicina Veterinária, Universidade Federal de Santa Maria, 2000.

GREENWOOD, D. Honey for superficial wounds and ulcers. The Lancet, v.341, p.90-91, 1993.

LAVALlE, G.E., ARAÚJO, R.B., PEREIRA, L.C. Uso de pericárdio bovino conservado em glicerina em cão - relato de caso. In: CONGRESSO BRASILEIRO DE CIRURGIA E ANESTESIOLOGIA VETERINÁRIA, 1998, Belo Horizonte, MG. Anais... Belo Horizonte : Colégio Brasileiro de Cirurgia e Anestesiologia Veterinária, 1998. 161p. p.109.

MAZZANTI, A. Músculo diafragma homólogo conservado em solução supersaturada de açúcar envolvido ou não com segmento omental para a reparação do diafragma de cão. Santa Maria, RS, 2000. 62p. Dissertação (Mestrado em Medicina Veterinária, área de concentração em Cirurgia) Programa de Pós-graduação em Medicina Veterinária, Universidade Federal de Santa Maria, 2000.

OLIVEIRA, L.O., PIPPI, N.L., GRAÇA, D.L., et al. Implante homógeno de bexiga conservada em glicerina a $98 \%$ para reparo da bexiga de cães. Arq Fac Vet UFRGS, v.27, n.1, p.90-102, 1999.

PIGOSSI, N. A glicerina na conservação de dura-mater estudo experimental. São Paulo, SP, 1967. 36p. Tese
(Livre docência) - Faculdade de Medicina de São Paulo, Universidade de São Paulo, 1967.

PIGOSSI, N. Implantação de dura-mater homógena conservada em glicerina. São Paulo, SP, 1964. 41p. Tese (Doutorado) - Faculdade de Medicina de São Paulo, Universidade de São Paulo, 1964.

POSTMES, T., BOGAARD, A.E., HAZEN, M. Honey for wounds, ulcers, and skin graft preservation. The Lancet, v. 341, p.756-757, 1993.

RAISER, A.G. Homoimplante ortotópico de tendão calcâneo comum, preservado em glicerina $98 \%$, e tratado com radiação laser arseneto de gálio, em cães. Santa Maria, RS, 2000. 80p. Tese (Doutorado, área de concentração em Cirurgia) - Programa de Pós-graduação em Medicina Veterinária. Universidade Federal de Santa Maria, 2000.

RANZANI, J.J.T., GANDOLFI, W. FRANCO, M., et al. Implante de pericárdio de eqüino preservado em glicerina em solução de continuidade do diafragma de cão. Brazilian Journal Veterinary Research Animal Science, v.27, n.1, p.75-81, 1990

RODGERS, B.M., MAHER, J.W., TALBERT, J.L. The use of preserved human dura for closure of abdominal wall and diaphragmatic defects. Annals Surgery, v.193, n.5, p.912920, 1981.

STOLF, N.A.G., AUN, F., TARIKI, J.Y., et al. O fechamento de comunicação interatrial com dura-máter homóloga preservada em glicerina. Rev Ass Med Brasil, v.19, n.5, p.175-178, 1978.

SUBRAHMANYAM, M. Storage of skin grafts in honey. The Lancet, v.341, p.63-64, 1993.

Ciência Rural, v. 32, n. 6, 2002. 